\title{
Clinical, Radiological, and Histopathological Patterns of Allergic Fungal Sinusitis: A Single- Center Retrospective Study
}

\begin{abstract}
Marzouqi A. Salamah ${ }^{1}$, Mazin Alsarraj ${ }^{2}$, Nawaf Alsolami ${ }^{3}$, Kamal Hanbazazah ${ }^{3}$, Abdulmajeed M. Alharbi 4 , Wael Khalifah Sr. 5

1. Otolaryngology-Head and Neck Surgery, Ohud Hospital, Al-Madinah Al-Munawarah, SAU 2. Otolaryngology-Head and Neck Surgery, King Fahad General Hospital, Jeddah, SAU 3. Otolaryngology-Head and Neck Surgery, King Fahad Armed Forces Hospital, Jeddah, SAU 4. Otolaryngology-Head and Neck Surgery, King Abdulaziz University Hospital, Jeddah, SAU 5. Otolaryngology-Head and Neck Surgery, Jeddah University, Jeddah, SAU
\end{abstract}

Corresponding author: Marzouqi A. Salamah, marzouqi.salamah@gmail.com

\section{Abstract \\ Objectives}

To explore the clinical, pathological, and imaging characteristics of allergic fungal sinusitis (AFS) and to analyze the correlation of disease duration with imaging and histopathology findings.

\section{Methods}

We reviewed all cases of AFS managed at the otorhinolaryngology department of King Fahad Armed Forces Hospital, Jeddah, Saudi Arabia. Demographic and clinical features were collected, as well as imaging and histopathological findings, which were analyzed by time from onset.

\section{Results}

Forty-six patients were diagnosed AFS, representing $11.8 \%$ of total sinusitis cases; 25 (54.3\%) were female, with mean (SD) age=33.57 (11.76). Patients presented with multiple symptoms of chronic rhinosinusitis (43, $93.5 \%)$, chronic headache ( $14,30.4 \%)$, and hyposmia $(2,4.3 \%)$, and 36 ( $78.3 \%)$ were diagnosed late ( $\geqslant 5$ years after onset). AFS involved all four sinuses in 32 (69.6\%) patients and was bilateral in $>53.5 \%$ of infected sinuses. Imaging showed increased intrasinus attenuation (88.2\%-95.3\%), complete opacification (74.4\%$85.3 \%$ ), sinus expansion (35.3\%-51.2\%), remodeling (20.6\%-37.2\%), wall thinning (41.2\%-58.1\%), and involvement of adjacent soft tissue (11.8\%-25.6\%), depending on the sinus type. Histology evidenced eosinophilic mucin (45.7\%), eosinophils (91.3\%), fungal hyphae (93.5\%), and Charcot-Leyden crystals (6.5\%). Patients who were diagnosed late had a higher percentage of imaging and pathological lesions, principally, the expansion and wall thinning of involved sinuses $(\mathrm{p}<0.050)$.

\section{Conclusion}

AFS represents a significant proportion of chronic sinusitis cases treated in the otorhinolaryngology department and is often diagnosed late with extensive forms. Major efforts should be made to improve the early diagnosis and management of such disease, including raising awareness about this entity among general practitioners and family physicians to enhance clinical suspicion and detection rate.

\section{Categories: Otolaryngology}

Keywords: allergic, eosinophilic, fungal sinusitis, imaging, histology, mucin

\section{Introduction}

Allergic fungal sinusitis (AFS), or eosinophilic fungal rhinosinusitis (EFRS), is a barely recognized pathologic entity that belongs to the fungal rhinosinusitis group [1]. It is broadly defined as a non-invasive fungal infection of sinuses inducing a marked type I hypersensitivity reaction that overshadows the clinical picture [2-3]. It is characterized by pathognomonic eosinophilic mucin-containing hyphae besides other distinctive histological and imaging features that contribute to the diagnosis [4-7].

We estimated the prevalence and explored the clinical, pathological, and imaging characteristics of AFS cases managed in our institution. We also analyzed the evolution over time of imaging and pathological findings and their correlation with hypereosinophilia.

\section{Materials And Methods}

This was a retrospective review of all cases of AFS that were diagnosed and treated at the otorhinolaryngology department of King Fahad Armed Forces Hospital (KFAFH), Jeddah, Saudi Arabia, 
between January 2009 and January 2019. Inclusion criteria were applied for patients with histologically confirmed non-invasive fungal sinusitis (IFS), which was carried out following signs suggestive of AFS on radiology (computed tomography $(\mathrm{CT})$ and magnetic resonance imaging (MRI)). Histological diagnosis was confirmed upon direct isolation of fungi microorganisms or the presence of fungal hyphae with eosinophilic mucin in the submucosa, blood vessels, and bone. The study excluded patients with other types of fungal sinusitis, including invasive fungal types, as well as patients with non-fungal sinusitis. The study was approved by the institutional review board of KFAFH.

Mucus and inflamed tissues were completely removed from all patients by functional endoscopic sinus surgery, with optional corticosteroid therapy by an intranasal or systemic route. Surgical specimens were examined intraoperatively to confirm the presence of eosinophilic mucin, identified as a firm and highly glutinous substance with a "peanut butter-like" color, which is highly suggestive of fungal sinusitis [7-8]. Subsequently, samples were collected in sterile normal saline bottles and referred to the histopathology and microbiology laboratories. Histologic examination was done by staining with Gomori's methenamine silver (GMS) and periodic acid-Schiff (PAS) to identify fungal structures. Fungal cultures were done by standard methods on Sabouraud's agar media [7].

The following data were collected: 1) demographic data, including age and gender; 2) clinical presentation, including time from onset, presenting symptoms, and the number of sinuses involved; 3) imaging findings, including sinus involved (sphenoid, maxillary, frontal, and/or ethmoid), side (right, left, or bilateral), presence of mucosal thickening, increased intrasinus attenuation, complete opacification, sinus expansion, remodeling, or wall thinning and the involvement of adjacent soft tissues in each involved sinus [9-10]; 4) laboratory data, including blood eosinophil rate, and pathology findings, including the presence of eosinophilic mucin, eosinophils, fungal hyphae, and Charcot-Leyden crystals; and 5) management, including therapeutic strategy and postoperative medication (antihistaminic agents, antifungal drops, corticosteroids, and antibiotics).

\section{Statistical methods}

Statistical analysis was performed with the Statistical Package for Social Sciences version 21.0 for Windows (IBM Corp., Armonk, NY). The prevalence of AFS was calculated as the percentage of patients diagnosed and treated as AFS among all cases of chronic rhinosinusitis treated in the same period; the result was presented as a percentage with a $95 \%$ confidence interval (95\% CI). Descriptive statistics were used to present the demographic and clinical characteristics, as well as the imaging and pathological characteristics. Imaging findings were described separately for sphenoid, frontal, maxillary, and ethmoid sinuses. Categorical variables are presented as frequency and percentage, while continuous variables are presented as mean \pm standard deviation (SD). Evolution over time of the imaging and pathological findings was analyzed by comparing patients with short disease duration (time from onset $<5$ years) with those having five to 10 years and a longer disease duration; the analysis used the chi-square test or Fisher's exact test, as appropriate. Further, the association of hypereosinophilia with demographic, clinical, and histopathological factors was analyzed using the chi-square test or Fisher's exact test, as appropriate. A p-value of $<0.05$ was considered to reject the null hypothesis.

\section{Results}

\section{Patients' demographic and clinical characteristics}

Forty-six patients were diagnosed with AFS in the institution, representing $11.8 \%$ of 390 cases of sinusitis treated in the same period. The demographics of the 46 cases showed that 25 (54.3\%) were female, mean (SD) age $=33.57$ (11.76) years, with $54.4 \%$ being above 30 years. On presentation, 43 (93.5\%) patients presented with multiple symptoms of chronic rhinosinusitis. Notably, 14 (30.4\%) patients complained of a chronic headache and two (4.3\%) of hyposmia. In medical history, we noted hypertension $(5,10.9 \%)$, asthma $(5,10.9 \%)$, and diabetes $(4,8.7 \%)$, while seven $(15.2 \%)$ had a history of sinus surgery. In the majority of cases, the diagnosis was made late, i.e., after $5+$ years of symptom onset $(36,78.3 \%)$ and had four sinuses involved (32, 69.6\%) (Table 1). 


\section{Cureus}

\begin{tabular}{|c|c|c|c|}
\hline Parameter & Category & Frequency & Percentage \\
\hline \multicolumn{4}{|l|}{ Demographics } \\
\hline \multirow[t]{2}{*}{ Gender } & Male & 21 & 45.7 \\
\hline & Female & 25 & 54.3 \\
\hline \multirow[t]{5}{*}{ Age } & Mean, SD & 33.57 & 11.76 \\
\hline & Up to 20 & 7 & 15.2 \\
\hline & $21-30$ & 14 & 30.4 \\
\hline & $31-40$ & 12 & 26.1 \\
\hline & $>40$ & 13 & 28.3 \\
\hline \multicolumn{4}{|l|}{ Miedical history } \\
\hline \multirow[t]{4}{*}{ Comorbidities } & Asthma & 5 & 10.9 \\
\hline & Diabetes & 4 & 8.7 \\
\hline & Hypertension & 5 & 10.9 \\
\hline & Other $\S$ & 8 & 17.4 \\
\hline \multirow[t]{2}{*}{ Past sinus surgery } & No & 39 & 84.8 \\
\hline & Yes & 7 & 15.2 \\
\hline \multicolumn{4}{|l|}{ Clinical picture } \\
\hline \multirow[t]{5}{*}{ Time from onset (years) } & Mean, SD & 7.57 & 3.19 \\
\hline & Median, interquartile & 9.00 & 5.00 \\
\hline & $<5$ & 10 & 21.7 \\
\hline & $5-<10$ & 18 & 39.1 \\
\hline & $10+$ & 18 & 39.1 \\
\hline \multirow[t]{5}{*}{ Presenting symptoms } & Multiple symptoms of chronic rhinosinusitis & 43 & 93.5 \\
\hline & Chronic headache & 14 & 30.4 \\
\hline & Hyposmia & 2 & 4.3 \\
\hline & Fever & 0 & 0.0 \\
\hline & Polyp (endoscopy) & 46 & 100.0 \\
\hline \multirow[t]{4}{*}{ No. sinuses involved } & 1 & 3 & 6.5 \\
\hline & 2 & 4 & 8.7 \\
\hline & 3 & 7 & 15.2 \\
\hline & 4 & 32 & 69.6 \\
\hline
\end{tabular}

\section{TABLE 1: Participants' demographic and clinical characteristics $(\mathrm{N}=46)$}

Values are frequencies and percentages, except if otherwise specified.

§ Other medical history included tympanoplasty (1 case), decreased vision (1), hypothyroidism (1), hepatitis B virus infection (1), G6PD deficit (1), end-stage renal disease (1), epilepsy (1), eczema \& food allergy (1); SD: standard deviation; G6PD: glucose-6-phosphate dehydrogenase

\section{Imaging findings}

Among all patients, fungal infection involved the sphenoid (40, 87.0\%), maxillary (43, 93.5\%), ethmoid (43, $93.5 \%$ ) and frontal $(34,73.9 \%)$ sinuses and was bilateral in $53.5 \%$ to $58.8 \%$ of all infected sinuses. All infected 


\section{Cureus}

sinuses presented mucosal thickening (100.0\%), and slight variations across the given sinus were observed regarding other CT imaging findings, including increased intrasinus attenuation (88.2\%-95.3\%), complete opacification (74.4\%-85.3\%), sinus expansion (35.3\%-51.2\%), remodeling (20.6\%-37.2\%), wall thinning (41.2\%-58.1\%), and involvement of adjacent soft tissue, including the medial orbital wall (11.8\%-25.6\%).

\section{Hypereosinophilia and histological findings}

Hypereosinophilia was found in 31 (67.4\%) patients, with no difference across gender ( $\mathrm{p}=0.243)$, age category ( $\mathrm{p}=0.948)$, or the number of sinuses involved $(\mathrm{p}=0.217)$; however, it was relatively more frequent in patients diagnosed at a relatively early stage, i.e. < five years from onset $(80.0 \%)$, compared to their counterpart (61.1\% -66.7\%), with no statistical significance ( $\mathrm{p}=0.591)$. Pathologically, eosinophilic mucin was present in $45.7 \%$ of patients and was inversely associated with hypereosinophilia ( $\mathrm{p}=0.047)$. Further, pathology was marked by the presence of eosinophils (91.3\%), fungal hyphae (93.5\%), Charcot-Leyden crystals (6.5\%), and other inflammatory cells (47.8\%) (Table 2 and Table 3).

\begin{tabular}{|c|c|c|c|c|c|c|c|c|c|c|c|c|}
\hline \multirow{3}{*}{ Parameter } & \multicolumn{12}{|c|}{ Sinus } \\
\hline & \multicolumn{3}{|c|}{ Sphenoid } & \multicolumn{3}{|c|}{ Maxillary } & \multicolumn{3}{|c|}{ Frontal } & \multicolumn{3}{|c|}{ Ethmoid } \\
\hline & $\mathrm{N}$ & $\% \mathrm{t}$ & $\% s$ & $\mathrm{~N}$ & $\% \mathrm{t}$ & $\% \mathrm{~s}$ & $\mathrm{~N}$ & $\% \mathrm{t}$ & $\% \mathrm{~s}$ & $\mathrm{~N}$ & $\% \mathrm{t}$ & $\% s$ \\
\hline Involvement & 40 & 87.0 & 100.0 & 43 & 93.5 & 100.0 & 34 & 73.9 & 100.0 & 43 & 93.5 & 100.0 \\
\hline \multicolumn{13}{|l|}{ Side } \\
\hline Right & 11 & 23.9 & 27.5 & 10 & 21.7 & 23.3 & 5 & 10.9 & 14.7 & 7 & 15.2 & 16.3 \\
\hline Left & 7 & 15.2 & 17.5 & 10 & 21.7 & 23.3 & 9 & 19.6 & 26.5 & 11 & 23.9 & 25.6 \\
\hline Bilateral & 22 & 47.8 & 55.0 & 23 & 50.0 & 53.5 & 20 & 43.5 & 58.8 & 25 & 54.3 & 58.1 \\
\hline Mucosal thickening & 40 & 87.0 & 100.0 & 43 & 93.5 & 100.0 & 33 & 71.7 & 97.1 & 43 & 93.5 & 100.0 \\
\hline Increased intrasinus attenuation & 38 & 82.6 & 95.0 & 41 & 89.1 & 95.3 & 30 & 65.2 & 88.2 & 39 & 84.8 & 90.7 \\
\hline Complete opacification $\S$ & 34 & 73.9 & 85.0 & 34 & 73.9 & 79.1 & 29 & 63.0 & 85.3 & 32 & 69.6 & 74.4 \\
\hline Expansion & 19 & 41.3 & 47.5 & 17 & 37.0 & 39.5 & 12 & 26.1 & 35.3 & 22 & 47.8 & 51.2 \\
\hline Remodelling & 13 & 28.3 & 32.5 & 9 & 19.6 & 20.9 & 7 & 15.2 & 20.6 & 16 & 34.8 & 37.2 \\
\hline Wall thinning & 22 & 47.0 & 55.0 & 20 & 43.5 & 46.5 & 14 & 30.4 & 41.2 & 25 & 54.3 & 58.1 \\
\hline Involvement of adjacent soft tissue & 8 & 17.4 & 20.0 & 7 & 15.2 & 16.3 & 4 & 8.7 & 11.8 & 11 & 23.9 & 25.6 \\
\hline
\end{tabular}




\section{Cureus}

\begin{tabular}{|c|c|c|c|}
\hline Parameter & Level & Frequency & Percentage \\
\hline \multicolumn{4}{|l|}{ Biology } \\
\hline \multirow[t]{2}{*}{ Eosinophils rate (\%) } & Normal (0-4) & 15 & 32.6 \\
\hline & High (>4) & 31 & 67.4 \\
\hline \multicolumn{4}{|l|}{ Histopathology } \\
\hline \multirow[t]{2}{*}{ Eosinophilic (allergic) mucin } & Absence & 25 & 54.3 \\
\hline & Presence & 21 & 45.7 \\
\hline \multirow[t]{2}{*}{ Eosinophils } & Absence & 4 & 8.7 \\
\hline & Presence & 42 & 91.3 \\
\hline \multirow[t]{2}{*}{ Fungal hyphae } & Absence & 3 & 6.5 \\
\hline & Presence & 43 & 93.5 \\
\hline \multirow[t]{2}{*}{ Charcot-Leyden crystals } & Absence & 43 & 93.5 \\
\hline & Presence & 3 & 6.5 \\
\hline \multirow[t]{6}{*}{ Other inflammatory cells } & Absence & 24 & 52.2 \\
\hline & Presence & 22 & 47.8 \\
\hline & Neutrophils & 12 & 26.1 \\
\hline & Lymphocytes & 14 & 30.4 \\
\hline & Plasma cells & 13 & 28.3 \\
\hline & Mononuclear cells & 1 & 2.2 \\
\hline
\end{tabular}

TABLE 3: Biological and histopathological findings in fungal sinusitis $(\mathrm{N}=46)$

\section{Management}

All patients underwent surgery $(46,100.0 \%)$. Prior to diagnosis, pharmaceutical prescriptions included antiallergic agents (40, 87.0\%), antibiotics (26, 56.5\%), and corticosteroids (15, 32.6\%); whereas antifungal drops were prescribed for only one patient (Figure 1). 


\section{Cureus}

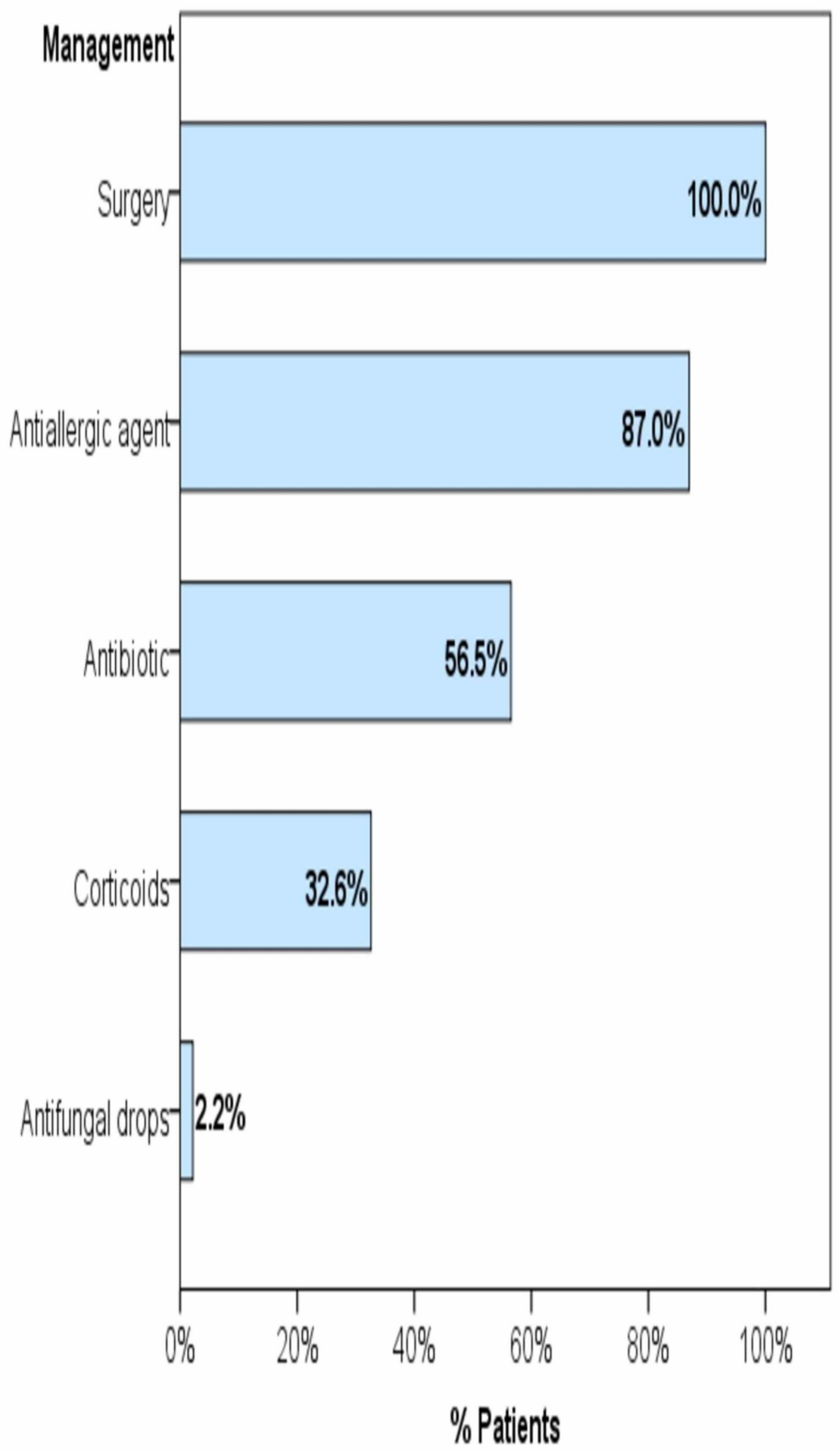

FIGURE 1: Management strategies of the cases of fungal sinusitis

Bars represent the percentage of patients who have received the given treatment

\section{Evolution over time of imaging and histopathology}

At an earlier stage (time from onset $<5$ years), sinus expansion and wall thinning are less commonly found in involved sinuses ( $30.0 \%$ and $20.0 \%$, respectively) than at a later stage ( $>55.6 \%$ and $>72.2 \%$, respectively); both associations are statistically significant ( $\mathrm{p}=0.018$ and 0.006 , respectively). Besides, patients with longer disease duration (time from onset $\geqslant 5$ years) are likely to have more frequent involvement of their four sinuses, with more frequent remodeling and involvement of adjacent tissue; however, these results were not statistically significant. Likewise, although not statistically significant, eosinophilic mucin and other inflammatory cells tend to be more frequent in patients with longer disease duration, while Charcot-Leyden crystals tend to be less frequent over time (Table 4 and Table 5). 


\section{Cureus}

\begin{tabular}{|c|c|c|c|c|}
\hline & \multicolumn{2}{|c|}{ Hypereosinophilia } & \multirow{2}{*}{ p-value } & \\
\hline & $\mathrm{N}$ & $\%$ & & \\
\hline \multicolumn{5}{|l|}{ Demographic factors } \\
\hline \multirow[t]{2}{*}{ Gender } & Male & 16 & 76.2 & \\
\hline & Female & 15 & 60.0 & .243 \\
\hline \multirow[t]{4}{*}{ Age } & Up to 20 & 5 & 71.4 & \\
\hline & $21-30$ & 10 & 71.4 & \\
\hline & $31-40$ & 8 & 66.7 & \\
\hline & $>40$ & 8 & 61.5 & .948 \\
\hline \multicolumn{5}{|l|}{ Clinical factors } \\
\hline \multirow[t]{3}{*}{ Time from onset (years) } & $<5$ & 8 & 80.0 & \\
\hline & $5-<10$ & 11 & 61.1 & \\
\hline & $10+$ & 12 & 66.7 & .591 \\
\hline \multirow[t]{4}{*}{ No. sinuses involved } & 1 & 1 & 33.3 & \\
\hline & 2 & 3 & 75.0 & \\
\hline & 3 & 3 & 42.9 & \\
\hline & 4 & 24 & 75.0 & .217 \\
\hline \multicolumn{5}{|l|}{ Histopathological factors } \\
\hline \multirow[t]{2}{*}{ Eosinophilic mucin } & Absence & 20 & 80.0 & \\
\hline & Presence & 11 & 52.4 & $.047^{\star}$ \\
\hline \multirow[t]{2}{*}{ Eosinophils } & Absence & 2 & 50.0 & \\
\hline & Presence & 29 & 69.0 & $.587^{\mathrm{F}}$ \\
\hline \multirow[t]{2}{*}{ Fungal hyphae } & Absence & 2 & 66.7 & \\
\hline & Presence & 29 & 67.4 & $1.000^{\mathrm{F}}$ \\
\hline \multirow[t]{2}{*}{ Charcot-Leyden Crystals } & Absence & 29 & 67.4 & \\
\hline & Presence & 2 & 66.7 & $1.000^{\mathrm{F}}$ \\
\hline \multirow[t]{2}{*}{ Other inflammatory cells } & Absence & 18 & 75.0 & \\
\hline & Presence & 13 & 59.1 & .250 \\
\hline
\end{tabular}

\section{TABLE 4: Factors associated with hypereosinophilia}

Test used: F, Fisher's exact test; otherwise, chi-square test. * statistically significant result $(p<0.05)$ 


\section{Cureus}

\begin{tabular}{|c|c|c|c|c|c|c|c|}
\hline \multicolumn{6}{|l|}{ Time from onset, years } & \multirow{3}{*}{ p-value } & \\
\hline$<5(\mathrm{~N}=10)$ & & \multicolumn{2}{|c|}{$5-<10(\mathrm{~N}=18)$} & \multicolumn{2}{|c|}{$10+(\mathrm{N}=18)$} & & \\
\hline $\mathrm{N}$ & $\%$ & $\mathrm{~N}$ & $\%$ & $\mathrm{~N}$ & $\%$ & & \\
\hline \multicolumn{8}{|l|}{ Imaging } \\
\hline \multicolumn{8}{|l|}{ No. Sinuses involved } \\
\hline 1 & 2 & 20.0 & 0 & 0.0 & 1 & 5.6 & \\
\hline 2 & 0 & 0.0 & 0 & 0.0 & 4 & 22.2 & \\
\hline 3 & 2 & 20.0 & 3 & 16.7 & 2 & 11.1 & \\
\hline 4 & 6 & 60.0 & 15 & 83.3 & 11 & 61.1 & .077 \\
\hline Mucosal thickening & 10 & 100.0 & 18 & 100.0 & 18 & 100.0 & - \\
\hline Increased intrasinus attenuation & 9 & 90.0 & 18 & 100.0 & 17 & 94.4 & .438 \\
\hline Complete opacification $\S$ & 8 & 80.0 & 17 & 94.4 & 16 & 88.9 & .500 \\
\hline Expansion & 3 & 30.0 & 15 & 83.3 & 10 & 55.6 & $.018^{\star}$ \\
\hline Remodeling & 2 & 20.0 & 11 & 61.1 & 7 & 38.9 & .097 \\
\hline Wall thinning & 2 & 20.0 & 14 & 77.8 & 13 & 72.2 & $.006^{*}$ \\
\hline Involvement of adjacent soft tissue & 1 & 10.0 & 9 & 50.0 & 5 & 27.8 & .082 \\
\hline \multicolumn{8}{|l|}{ Histopathology } \\
\hline Eosinophilic mucin & 2 & 20.0 & 9 & 50.0 & 10 & 55.6 & .174 \\
\hline Eosinophils & 9 & 90.0 & 17 & 94.4 & 16 & 88.9 & .828 \\
\hline Fungal hyphae & 9 & 90.0 & 18 & 100.0 & 16 & 88.9 & .354 \\
\hline Charcot-Leyden crystals & 2 & 20.0 & 1 & 5.6 & 0 & 0.0 & .119 \\
\hline Other inflammatory cells & 3 & 30.0 & 8 & 44.4 & 11 & 61.1 & .269 \\
\hline
\end{tabular}

TABLE 5: Over time evolution of imaging and histopathology findings $(\mathrm{N}=46)$

$\S$ Of at least one side; * statistically significant difference; test used: chi-square test

\section{Discussion}

\section{Summary of findings}

In this single-center, retrospective chart review, AFS is found in approximately $11.8 \%$ of patients who presented at otorhinolaryngology for chronic rhinosinusitis. Patients with AFS are often diagnosed late, at an advanced disease stage, and present with atypical symptomatology. CT imaging revealed a high percentage of multiple and bilateral sinus involvement, with a considerable ratio of bone and tissue damage, including remodeling, wall thinning, and the involvement of adjacent soft tissue that increases with disease duration. Pathology was dominated by the presence of eosinophils and fungal hypha, while eosinophilic mucin was present in approximately half of the patients.

\section{Case definition of AFS}

The definition and diagnostic criteria of AFS are still under debate, and minor progress has been made in the last two decades to achieve a consensus [11]. Historically, the concept of the combined allergic and fungal pathological processes in sinuses was first described in 1976 by Safirstein, who reported the case of allergic bronchopulmonary aspergillosis simultaneously involving the patient's sinuses [12]. Subsequently, several similar cases were reported and different lists of criteria were suggested based on each author's clinical experience and the available literature then. These criteria included the characteristic eosinophilic-mucin containing hyphae, along with a positive fungal strain or culture, in the absence of tissue invasion by fungi, in addition to other suggestive (or supportive) clinical and biological evidence of an allergy such as positive atopic history, nasal polyposis, absence of immunodeficiency, and elevation of total or specific 
immunoglobulin E (IgE) or a positive skin test to fungal antigens [5,13-15]. However, these diagnostic criteria were not constantly reported in the literature, and the clinical picture overlapped with other entities of non-allergic fungal sinusitis in a considerable number of reported cases [16]. This is consistent with our study showing the presence of sinus polyposis on endoscopic examination, in $100 \%$ of cases, while characteristic eosinophilic mucin was present in less than half. On the other hand, the strict application of the aforementioned criteria may lead to several AFS cases going undiagnosed.

More recently, while several researchers debated the role of fungi in the genesis of AFS [17-21], others attempted to establish the immunologic difference between AFS and other types of chronic rhinosinusitis by highlighting the major role of allergy evidenced by significantly higher levels of allergy markers, such as total IgE, IgG anti-Alternaria-specific antibodies (UniCAP 100), and IgE antifungal antibodies in the sera of patients with AFS [22]. In the present study, the blood eosinophils rate was the only biological marker of allergy that was available in patients' files, which was found to be elevated in two-thirds of the patients (67.3\%), and was relatively more frequent in patients diagnosed at an early stage (80.0\%).

\section{A varying prevalence}

Lack of consensus on AFS case definition, along with the relative rarity of the disease, further resulted in a fluctuating epidemiological picture, with a prevalence ranging between $5 \%$ and $27 \%$ of refractory chronic rhinosinusitis cases [23], $6 \%$ and $9 \%$ of rhinosinusitis cases requiring surgery [14], and $9 \%$ and $12 \%$ in sinonasal polyposis [24-25]. The highest figures were reported in India, where the prevalence of AFS was estimated to be between $56 \%$ and $79 \%$ of all cases of chronic rhinosinusitis [26-29]. Comparably, in the present study, AFS cases represented $11.2 \%$ of the total cases of chronic sinusitis that required surgical treatment.

\section{Highly presumptive clinical and radiological signs}

In routine practice, the diagnosis of AFS is suspected on a set of clinical and radiological arguments, then confirmed by an intraoperative examination of mucin and pathological and microbiological examinations postoperatively [1-11]. The present study highlighted several clinical signs that should lead the physician to suspect AFS. Together, these signs outline a clinical picture of chronic, non-febrile rhinosinusitis involving multiple sinuses and developing for several years, which does not respond to standard treatment. Classically, the literature reports the young age of the patient and te=he absence of pain as additional alerting signs [30], which is consistent with the young population (mean age $~ 34$ years) and the low percentage of headache $(\sim 30 \%)$ in the present study. Radiologically, mucosal thickening was constantly found, and involved sinuses were completely opacified with increased intrasinus attenuation in majority cases, while signs of tissue and bone damage were less frequent and likely to be associated with advanced stage. In agreement with these findings, the literature exposes a set of radiological criteria, including typical opacifications with central hyper-attenuation in a CT scan, with the highlight of multiple sinus involvement. Additionally, eosinophilic mucin is characteristically identified by central low T1 and T2 void, as a result of its high protein concentration and low free water and mineral content in mucin. Besides, bone damage, including skull base erosion and/or orbital erosion, are reported to be relatively frequent (up to 56\%) and are considered distinctive of AFS from non AFS [11].

\section{Promoting specialist referral to enhance early detection}

Acknowledgment of the aforementioned clinical and radiological arguments should systematically lead to the referral of the patient to an otorhinolaryngology specialist. However, to effectively enhance early detection, specialist referral should be encouraged for any case of chronic rhinosinusitis in atopic individuals, with the absence of bacterial infection signs and failure to respond to conventional treatments. This simple take-home message should be disseminated among general practitioners (GPs) and family physicians, as well as the general population, thereby enabling timely and appropriate management by the specialist to reduce the risk of irreversible damage.

\section{Towards a new diagnostic approach}

While no consensus could be reached regarding the diagnostic criteria, a comprehensive approach based on the distinctive pathophysiological features might be more relevant to address the AFS diagnosis. According to the updated classifications, AFS is described as a fundamentally immunoallergic pathologic process that is triggered and eventually sustained by fungi colonization. That is, the main symptomatology is explained by an allergy-mediated inflammatory process, and this could be considered as the Comprehensive Criterion number one (CC1) in the proposed diagnostic approach of AFS. Comprehensive Criterion number two (CC2) would theoretically be the presence of fungi, which can be evidenced by pre- or postoperative mycological examination of the sinus and nasal mucus. On the other hand, the non-invasiveness of the mucous membrane by fungi (CC3) constitutes the frontier that separates AFS from invasive forms of fungal sinusitis, which is a genuine chronic fungal infection commonly observed in immunosuppressed patients [11]. Based on this paradigm, the proposed new diagnostic approach assumes that each of these three comprehensive criteria could be fulfilled by relevant clinical, biological, radiological and pathological, and microbiological signs, the combination of which may differ from a patient to another. 


\section{Limitations}

The main limitation of this study is the lack of relevant clinical and biological data such as the immune status of the patients, the history of nasal polyposis, total and fungal-specific IgE, and so on, which are mainly imputable to the retrospective design. Furthermore, follow-up data, such as success rate, recurrence rate, time to recurrence, etc., were missing and could provide valuable insight into treatment efficacy.

\section{Conclusions}

AFS patients represent a significant percentage among cases of chronic sinusitis treated in otorhinolaryngology and are often diagnosed late, with extensive forms. Major efforts should be made to enhance the early diagnosis and management of such disease, in order to improve the outcome and reduce the risk of irreversible damage. Such measures include raising awareness about this entity among general practitioners and family physicians to enhance clinical suspicion and encourage referral to specialists of any case of refractory chronic rhinosinusitis. Given the continuous controversy regarding the definition and diagnosis criteria of AFS, we proposed a new diagnostic approach, which assumes an immunoallergic component, the presence of fungi, and the absence of mucous membrane invasion by fungi as comprehensive criteria that may be fulfilled by relevant clinical, biological, radiological and pathological, and microbiological signs; the combination of which may differ from one patient to another.

\section{Additional Information \\ Disclosures}

Human subjects: Consent was obtained by all participants in this study. Animal subjects: All authors have confirmed that this study did not involve animal subjects or tissue. Conflicts of interest: In compliance with the ICMJE uniform disclosure form, all authors declare the following: Payment/services info: All authors have declared that no financial support was received from any organization for the submitted work. Financial relationships: All authors have declared that they have no financial relationships at present or within the previous three years with any organizations that might have an interest in the submitted work. Other relationships: All authors have declared that there are no other relationships or activities that could appear to have influenced the submitted work.

\section{References}

1. Chakrabarti A, Denning DW, Ferguson BJ, et al.: Fungal rhinosinusitis. Laryngoscope. 2009, 119:1809-1818. 10.1002/lary.20520

2. Challa S, Uppin SG, Hanumanthu S, et al.: Fungal rhinosinusitis: a clinicopathological study from South India. Eur Arch Otorhinolaryngol. 2010, 267:1239-1245. 10.1007/s00405-010-1202-6

3. Lackner A, Stammberger H, Buzina W, Freudenschuss K, Panzitt T, Schosteritsch S, Braun H: Fungi: a normal content of human nasal mucus. Am J Rhinol. 2005, 19:125-129.

4. Allergic fungal sinusitis. (2016). http://www.pathologyoutlines.com/topic/nasalallergicfungal.html.

5. Meltzer EO, Hamilos DL, Hadley JA, et al.: Rhinosinusitis: establishing definitions for clinical research and patient care. J Allergy Clin Immunol. 2004, 114:155-212. 10.1016/j.jaci.2004.09.029

6. Glass D, Amedee RG: Allergic fungal rhinosinusitis: a review. Ochsner J. 2011, 11:271-275.

7. Montone KT: Pathology of fungal rhinosinusitis: a review. Head Neck Pathol. 2016, 10:40-46. 10.1007/s12105-016-0690-0

8. Schubert MS: Allergic fungal sinusitis: pathophysiology, diagnosis and management . Med Mycol. 2009, 47:324-330. 10.1080/13693780802314809

9. Mukherji SK, Figueroa RE, Ginsberg LE, et al.: Allergic fungal sinusitis: CT findings . Radiology. 1998, 207:417-422. 10.1148/radiology.207.2.9577490

10. Wise SK, Rogers GA, Ghegan MD, Harvey RJ, DelGaudio JM, Schlosser RJ: Radiologic staging system for allergic fungal rhinosinusitis (AFRS). Otolaryngol Neck Surg. 2009, 140:735-740. 10.1016/j.otohns.2008.12.053

11. Chakrabarti A, Kaur H: Allergic Aspergillus rhinosinusitis. J Fungi. 2016, 2:32. 10.3390/jof2040032

12. Safirstein BH: Allergic bronchopulmonary aspergillosis with obstruction of the upper respiratory tract . Chest. 1976, 70:788-790. 10.1378/chest.70.6.788

13. Deshazo R, Swain R: Diagnostic criteria for allergic fungal sinusitis. J Allergy Clin Immunol. 1995, 96:24-35. 10.1016/s0091-6749(95)70029-3

14. Bent JP, Kuhn FA: Diagnosis of allergic fungal sinusitis. Otolaryngol Neck Surg. 1994, 111:580-588. 10.1177/019459989411100508

15. Cody DT, Neel HB, Ferreiro JA, Roberts GD: Allergic fungal sinusitis: the Mayo clinic experience . Laryngoscope. 1994, 104:1074-1079. 10.1288/00005537-199409000-00005

16. Ferguson BJ: Eosinophilic mucin rhinosinusitis: a distinct clinicopathological entity . Laryngoscope. 2000, 110:799-813. 10.1097/00005537-200005000-00010

17. Shin SH, Ponikau JU, Sherris DA, et al.: Chronic rhinosinusitis: an enhanced immune response to ubiquitous airborne fungi. J Allergy Clin Immunol. 2004, 114:1369-1375. 10.1016/j.jaci.2004.08.012

18. Sasama J, Sherris DA, Shin SH, Kephart GM, Kern EB, Ponikau JU: New paradigm for the roles of fungi and eosinophils in chronic rhinosinusitis. Curr Opin Otolaryngol Head Neck Surg. 2005, 13:2-8.

19. Al-Amin ZM, Thomson M, Al-Qattan KK, Peltonen-Shalaby R, Ali M: Anti-diabetic and hypolipidaemic properties of ginger (Zingiber officinale) in streptozotocin-induced diabetic rats. Br J Nutr. 2006, 96:660666. 10.1016/j.jaci.2006.06.035

20. Fokkens WJ, van Drunen C, Georgalas C, Ebbens F: Role of fungi in pathogenesis of chronic rhinosinusitis . 


\section{Cureus}

Curr Opin Otolaryngol Head Neck Surg. 2012, 20:19-23. DOI: 10.1079/bjn20061849

21. Ponikau JU, Sherris DA: The role of airborne mold in chronic rhinosinusitis . J Allergy Clin Immunol. 2006, 118:762-763. 10.1097/MOO.0b013e32834e9084

22. Hutcheson PS, Schubert MS, Slavin RG: Distinctions between allergic fungal rhinosinusitis and chronic rhinosinusitis. Am J Rhinol Allergy. 2010, 24:405-408. 10.2500/ajra.2010.24.3533

23. Goh BS, Gendeh BS, Rose IM, Pit S, Samad SA: Prevalence of allergic fungal sinusitis in refractory chronic rhinosinusitis in adult Malaysians. Otolaryngol Neck Surg. 2005, 133:27-31. 10.1016/j.otohns.2005.03.028

24. Telmesani LM: Prevalence of allergic fungal sinusitis among patients with nasal polyps . Ann Saudi Med. 2009, 29:212-214. 10.5144/0256-4947.2009.212

25. Das A, Bal A, Chakrabarti A, Panda N, Joshi K: Spectrum of fungal rhinosinusitis; histopathologist's perspective. Histopathology. 2009, 54:854-859. 10.5144/0256-4947.2009.212

26. Bakhshaee M, Fereidouni M, Mohajer MN, Majidi MR, Azad FJ, Moghiman T: The prevalence of allergic fungal rhinosinusitis in sinonasal polyposis. Eur Arch Otorhinolaryngol. 2013, 270:3095-3098. 10.1111/j.1365-2559.2009.03309.x

27. Chakrabarti A, Rudramurthy SM, Panda N, Das A, Singh A: Epidemiology of chronic fungal rhinosinusitis in rural India. Mycoses. 2015, 58:294-302. 10.1111/myc.12314

28. Prateek S, Banerjee G, Gupta P, Singh M, Goel MM, Verma V: Fungal rhinosinusitis: a prospective study in a university hospital of Uttar Pradesh. Indian J Med Microbiol. 2013, 31:266-269. 10.4103/0255-0857.115634

29. Manning SC, Holman M: Further evidence for allergic pathophysiology in allergic fungal sinusitis . Laryngoscope. 1998, 108:1485-1496. 10.1097/00005537-199810000-00012

30. Michael RC, Michael JS, Ashbee RH, Mathews MS: Mycological profile of fungal sinusitis: an audit of specimens over a 7-year period in a tertiary care hospital in Tamil Nadu. Indian J Pathol Microbiol. 2008, 51:493-496. 10.1097/00005537-199810000-00012 